\title{
Advenimientos de lo real: psicoanálisis y política del síntoma
}

\author{
Fernando Martínez
}

\begin{abstract}
Resumen
El propósito del trabajo es destacar el dispositivo analítico como un espacio político en acto para el tratamiento de lo real en la época. Podemos señalar, con Lacan, que lo real que adviene por efectos de la ciencia en su articulación con la economía de mercado introduce, por una vía política, sus consecuencias sobre la subjetividad. En la experiencia de la práctica analítica nos encontramos con la forma singular del síntoma ante los advenimientos de lo real de la época; donde, en muchos casos, la precariedad del lazo social, la banalización de la palabra consumida en "packs" disfrazada de discurso y otra serie de manifestaciones redoblan la apuesta del psicoanalista: restituir el estatuto al sujeto del inconsciente. Es en ese acto ético y político donde el descubrimiento freudiano mantiene su vigencia, no sin redimensionar el lugar del analista en el malestar en la cultura. Produciendo de un advenimiento un acontecimiento que trastoca la posición del sujeto.
\end{abstract}

\section{Palabras clave:}

Advenimiento de lo real; Evento; Real.

\section{Advents of the real: psychoanalysis and symptom politics}

\begin{abstract}
The purpose of the work is to highlight the analytical device as a political space in act for the treatment of the real at the time. We can point out, with Lacan, that the real that comes from the effects of science in its articulation with the market economy introduces, by a political route, its consequences on subjectivity. In the experience of analytic practice we find the singular form of the symptom before the advents of the real of the epoch; where, in many cases, the precariousness of the social bond, the banalization of the word consumed in "packs" disguised as discourse and another series of manifestations redouble the bet of the psychoanalyst: to restore the status to the subject of the unconscious. It is in that ethical and political act where the Freudian discovery maintains its validity, not without
\end{abstract}


redimensioning the place of the analyst in the malaise in the culture. Producing from an advent an event that upsets the position of the subject.

\title{
Keywords:
}

Advent of the real; Event; Real.

\section{Adventos do real: psicanálise e política do sintoma}

\begin{abstract}
Resumo
O objetivo deste trabalho é destacar o dispositivo analítico como um espaço político em ato para o tratamento do real da época. Podemos apontar, com Lacan, que o real que advém dos efeitos da ciência em sua articulação com a economia de mercado introduz, por uma via política, suas implicações na subjetividade. $\mathrm{Na}$ experiência da prática analítica, encontramo-nos com uma forma singular do sintoma diante dos adventos do real da época, em que, em muitos casos, a precariedade do laço social, a banalização da palavra consumida em "packs" disfarçados de discurso e outra série de manifestações redobram a aposta do psicanalista: restituir o estatuto ao sujeito do inconsciente. É nesse ato ético e político que a descoberta freudiana mantém-se vigente, não sem redimensionar o lugar do analista no mal-estar na cultura, produzindo, a partir de um advento, um acontecimento que modifica a posição do sujeito.
\end{abstract}

\section{Palavras-chave:}

Advento do real; Acontecimento; Real.

\section{Avènement du réel : psychanalyse et politique symptomatique}

\section{Résumé}

Le but du travail est de mettre en évidence le dispositif analytique en tant qu'espace politique en acte pour le traitement du réel à l'époque. On peut souligner, avec Lacan, que le réel issu des effets de la science dans son articulation avec l'économie de marché introduit, par voie politique, ses conséquences sur la subjectivité. Dans l'expérience de la pratique analytique, nous trouvons la forme singulière du symptôme avant les avancées du réel de l'époque; où, dans de nombreux cas, la précarité des liens sociaux, la banalisation du mot consommé dans les " paquets " déguisés en discours et d'autres séries de manifestations une autre série de manifestations redoublent le pari du psychanalyste: restaurer l'état au sujet de 
l'inconscient. C'est dans cet acte éthique et politique que la découverte freudienne maintient sa validité, non sans redimensionner la place de l'analyste dans le malaise de la culture. Produire à partir d'un avènement un événement qui bouleverse la position du sujet.

\section{Mots-clés :}

Avènement du réel ; Événement ; Réel.

Para ilustrar el recorrido de una cura analítica que, apuesta al tratamiento de lo real advenido, comenzaré por señalar una simple diferencia entre advenimiento y acontecimiento. Me interesa marcar esta diferencia entre los términos dado que muchas veces se usan como sinónimos, pero el advenimiento refiere a la acción de llegar, suceder, sobrevenir; muy ligado a la liturgia religiosa, en cambio el acontecimiento es ya una situación que, por contar con alguna característica extraordinaria, adquiere relevancia y logra llamar la atención, por lo que presupone cierta sanción subjetiva.

El acontecimiento produce un corte con el sentido establecido y provoca uno nuevo, tal es el Acontecimiento Freud en la cultura que trastoca lo establecido y que, a grandes rasgos, produce una modificación en el modo de leer lo humano.

Entonces, ¿Cómo un advenimiento de lo real deviene acontecimiento en el sujeto que quiebra con el sentido y conmueve su posición?

Un acontecimiento es una construcción lógica posterior a un advenimiento de lo real. Dado que un real carece de sentido, es necesario que el sujeto pueda sancionar eso que adviene como éxtimo. Un sujeto que es a la vez conmovido e implicado en esa ajenidad propia.

El comienzo de un análisis es un acontecimiento iniciático, dado que anoticia al sujeto de su propio ICC, de aquello que adviene fuera de discurso: un fallido, un lapsus, un sueño o un síntoma son acontecimientos de algún advenimiento de lo real en tanto haya un sujeto que sancione allí la ex-sistencia de eso, como una formación de su inconsciente. Que un fallido es realmente un fallido y quiere decir otra cosa y no es una equivocación, por ejemplo. En tal sentido podemos pensar la queja como una señal no descifrada del advenimiento de lo real y, ya en su formalización como síntoma analítico, ubicar una manera de tratamiento del real en juego. Para que esta operación tome cuerpo se torna necesario el encuentro con el deseo del analista y la apuesta al giro de discurso de manera tal que: "sólo una intervención de la interpretación puede sostener que el acontecimiento está presentado en la situación, en tanto advenimiento al ser del no-ser, advenimiento a lo visible de lo invisible" (Badiou, 2015, p. 204). 
La maniobra interpretativa del inicio, fundante de la cura, genera un acontecimiento que conmueve los dichos y permite el tratamiento del advenimiento de lo real del decir en el sujeto, implicando la política del psicoanálisis, la incidencia del discurso analítico que apuesta a la diferencia absoluta, al cauce que el propio sujeto pueda dar en el tratamiento a su modo irreductible de gozar concernido en su síntoma como coalescencia entre significante y goce en tanto "es lo más real que hay en el sujeto a-sustancial producido por el significante” (Soler, 2017, p. 2). Esta apuesta al uno por uno y a lo que acontece de real en cada sujeto, es una apuesta ética que se sostiene en ese lazo social particular entre el analizante y el analista; donde radica la vigencia del psicoanálisis, en este contexto social donde los lazos se encuentran amenazados por la hegemonización de un mercado que forcluye al sujeto y promueve la instrumentalización de las individualidades.

En nuestra práctica, recibimos sujetos que señalan en su queja la afectación gozosa del cuerpo por el significante, agravada muchas veces por esta fragilidad del lazo social actual. Se trata de un real ya advenido, el dispositivo analítico, sostenido en la transferencia, que propicia un giro en el discurso donde el sujeto puede anudarse en el decir y experimentar allí un acontecimiento, un fuera/ dentro moebiano de sentido: novedad que lo sustrae de la queja y lo relanza a la posibilidad del acto, sobreponiéndose.

Podemos encontrar a la altura del Seminario 21 una referencia a la diferencia entre advenimiento de lo real y acontecimiento del decir, sustentado en la temporalidad del nudo tal como lo señala Sandra Berta en su pretexto; allí Lacan incluye al acontecimiento del decir como escritura del nudo diferenciando el acontecimiento simbólico, real e imaginario: "El acontecimiento, él, el acontecimiento no se produce sino en el orden de lo simbólico. No hay acontecimiento sino del decir" (Lacan, 1974). Es preciso tiempo para escribir el nudo del decir, nudo del parlêtre que hace al trauma borromeano (Berta, 2017, p. 2).

Advenimiento de lo real/acontecimiento en lo simbólico, como una forma de escritura del decir en el transcurso del análisis, acontecimiento de lo real advenido del trou-matisme, que provoca un nuevo advenimiento desplegado en la cura, un re-advenimiento de lo real: acontecimientos de un decir que evocan lo real advenido en lo traumático.

Cabe diferenciar entonces; lo real advenido sin implicancia subjetiva: queja que lo señala sin que sea un acontecimiento del decir en el sujeto; el re-advenimiento de lo real en transferencia que acontece en el decir en la cura y, un punto de superposición entre este re-advenimiento y el acontecimiento del acto en el final del análisis: sólo el vacío nombra lo que hay en común (Badiou, 2015, p. 208) entre el advenimiento de lo real y el acontecimiento del final. 
Los ecos de ese vacío del real adcontecido en el final de la cura, que nos llegan desde el dispositivo del pase, son ecos que enuncian y que transmiten un rasgo, forma simple de la marca traumática del origen del significante, matriz de la repetición inaugural, cicatrices de lo real advenido.

\section{Referencias bibliográficas}

Badiou, A. (2015). El ser y el acontecimiento. Buenos Aires: Alfaguara.

Berta, S. (2017, Mayo). Pretexto 2 a la X Cita de la IF-EPFCL "Acontecimiento y advenimiento de lo real".

Lacan, J. (1974). El seminario, libro 21: los no incautos yerran. 15 de enero de 1974. Inédito.

Soler, C. (2017). Advenimientos de lo real. (Rithée Cevasco, Trad.). 27 de mayo de 2017. Intervención en la ciudad de Gijón, Asturias, España. Invitación del DEL de la EPFCL-España-F9 en el marco de las XVII Jornadas de sus Colegios Clínicos.

Recebido: $21 / 08 / 2018$

Aprovado: 19/11/2018 